\title{
Frequency of P16INK4a and P14ARF genes methylation and its impact on bladder cancer cases in north Indian population
}

\author{
Seyed Ali Hosseini ${ }^{\mathrm{a}, \mathrm{b}, *}$, Ranbir Chander Sobti ${ }^{\mathrm{a}, *}$, Kianoosh Malekzadeh ${ }^{\mathrm{a}}$, Shrawan Kumar Singh $^{\mathrm{c}}$ and \\ Kusum Joshi ${ }^{\mathrm{d}}$ \\ ${ }^{a}$ Department of Biotechnology, Panjab University, Chandigarh, India \\ ${ }^{\mathrm{b}}$ Department of Medical Genetics, National Institute of Genetic Engineering and Biotechnology, Tehran, Iran \\ ${ }^{\mathrm{c}}$ Department of Urology, Post Graduate of Medical Education and Research, Chandigarh, India \\ ${ }^{\mathrm{d}}$ Department of Histopathology, Post Graduate of Medical Education and Research, Chandigarh, India
}

\begin{abstract}
Introduction: Amongst the genitourinary cancers, carcinoma of the urinary bladder is one of the leading causes of death in India. Hypermethylation of the $\mathrm{CpG}$ islands of gene promoter is one of the earliest and most frequent epigenetic alterations leading to cancer as well as in its development. Several studies have suggested that tumour suppressor genes play a key role in the development of cancer. Methylation in the $C D K N 2 A$ has been associated with various malignant diseases, but information with respect to urinary bladder cancer is lacking in north Indian population.

Materials and methods: We analyzed the methylation of P16INK4a and P14ARF in 80 tissues and matched blood samples of patients suffering from bladder cancer and 80 blood samples of cancer-free individuals by MS-PCR.

Results: In tissue and matched blood samples of bladder cancer patients, the incidence of P14ARF hypermethylation significantly increased $(\mathrm{OR}=0.31,95 \% \mathrm{CI}=0.12-0.8, P=0.01)$ and $(\mathrm{OR}=0.0,95 \% \mathrm{CI}=0.0-0.62, P=0.006)$ respectively with an increase in age. Clinicopathological analysis revealed that $P 14 A R F$ hypermethylation in tissue and blood samples was significantly associated with invasive stage $(\geqslant \mathrm{T} 2)(\mathrm{OR}=0.21,95 \% \mathrm{CI}=0.08-0.51, P=0.0002)$ and $(\mathrm{OR}=0.09,95 \% \mathrm{CI}=0.03-0.37, P=$ $0.00001)$ respectively. Muscle invasive tumour stage $(\geqslant \mathrm{T} 2)$ showed significant association with increased risk of $P 16 I N K 4 \alpha$ promoter hypermethylation in tissue and blood samples of patients $(\mathrm{OR}=0.38,95 \% \mathrm{CI}=0.17-0.82, P=0.01)$ and $(\mathrm{OR}=$ $0.13,95 \% \mathrm{CI}=0.05-0.36, P=0.00005)$ respectively.

Conclusion: These results suggest that the $\mathrm{CpG}$ island hypermethylation status of the defined panel of genes may be a useful biomarker in patients suffering from bladder cancer.
\end{abstract}

Keywords: Bladder cancer, methylation, tumour suppressor gene, P14ARF, P16INK4a

\section{Introduction}

Bladder cancer (BC) represents $2 \%$ of all human malignancies. It is estimated that more than 68,810 new patients were to be diagnosed with $\mathrm{BC}$ in the United States in 2008 and 14,100 patients are expected to die

* Corresponding authors: Seyed Ali Hosseini and Ranbir Chander Sobti, Department of Biotechnology, Panjab University, Chandigarh, 160014, India. Tel.: +91 172 2541409; E-mail: dralihosseini@ yahoo.com. of this disease [1]. In India carcinoma of the urinary bladder is one of the leading causes of death, amongst the genitourinary cancers [2]. Several chemical and environmental exposures have been linked to the development of bladder cancer. However, in most cases, it has been difficult to establish a causality relation due to the long period between exposure and development of clinical sings [3]. Cigarette smoking is the most important risk factor for bladder cancer and is thought to be responsible for 1 to 2 of every three newly diagnosed cases of bladder cancer [4]. 
About $95 \%$ of bladder neoplasms are transitional cell carcinomas. The remainder are squamous tumours, adenocarcinomas, and other subtypes. At the time of diagnosis, $>60 \%$ of the transitional carcinomas are papillary noninvasive (Ta), 10-20\% show invasion limited to the lamina propria (T1), and $20 \%$ present muscle or deeper infiltration (T2-T4) [5]. Bladder cancer is the result of monoclonal genetic changes, and the multiple synchronous or metachronous tumours are derived from micrometastatic foci that have migrated from the original site rather than from a polyclonal mutation [68].

Cancer is a polygenetic and polyepigenetic disease [9]. Hypermethylation of the CpG islands of gene promoter is one of the earliest and most frequent epigenetic alterations found in cancer $[10,11]$ as well as its development [12]. It is an important epigenetic mechanism for gene silencing, which may confer tumour cells on growth advantage [10,13]. Many cellular pathways are inactivated by this epigenetic event, including DNA repair (BRCA1, MGMT), cell cycle regulation (p16INK4a, p15INK4a, Rb, p14ARF), apoptosis $(D A P K, T M S 1)$, cell adherence, drug resistance, detoxification, differentiation, angiogenesis and metastasis [12,14].

The specific patterns of $\mathrm{CpG}$ island hypermethylation between tumour types may provide a useful signature for tumour diagnosis and prognosis $[15,16]$. Moreover, genes that are frequently methylated in specific tumours have been used as molecular targets for the detection of neoplastic cells in body fluids such as urine and plasma. These genes provide additional targets for noninvasive early diagnosis and monitoring of cancers $[17,18]$.

Tumour suppressor genes prevent cells from malignant transformation. Tumour suppressor genes function by one of the following mechanisms: protect the genome from mutagenic events, impede dysregulated progression through the cell cycle, induce apoptosis in cells that escape normal cell cycle controls, and inhibit cellular migration and metastasis. Classically, tumour suppressor genes have been described to acquire loss of function mutations or deletions leading to their inability to delay malignant transformation. Alternatively, epigenetic events, such as methylation, represent a distinct mechanism of tumour suppressor gene inactivation. Aberrant gene promoter methylation of these genes has been known to be associated with gene silencing and is functionally equivalent to a deleted gene [19].

Application of novel molecular biology techniques has increased our appreciation of the widespread changes in methylation patterns that occur during urinary bladder carcinogenesis. Hypermethylation occur throughout all stages of tumourigenesis, including the early phases, and is increasingly recognized as a major mechanism involved in tumour suppressor genes silencing or inactivation [20].

A large number of genes have been reported to be hypermethylated in bladder cancer. Some examples include the ploINK4a (at $C D K N 2 A^{\mathrm{INK} 4 \mathrm{a}}$ locus on chromosome 9p21), E-cadherin ( $C D H 1$, encoding a transmembrane glycoprotein that modulates calcium-dependent intercellular adhesion), and RASSF 1A (ras association domain family gene 1, isoform A) genes [21-23]. Inactivation of the CDKN2A genetic locus, due to mutations, homozygous deletion and promoter methylation, have also been reported at varying frequencies [24-26]. The well characterized $C D K N 2 A$ locus at $9 \mathrm{p} 21$ encodes two unrelated cell cycle inhibitors, $p 16 I N K 4 a$ (referred to as p16 throughout) and $p 14 A R F$ (referred to as ARF throughout) from a partially shared genomic sequence, which function upstream of $R b$ and $p 53$, respectively [27]. P14ARF and P16INK4a are indicated as candidates for hypermethylation-associated inactivation, because they contain documented $\mathrm{CpG}$ islands that can be silenced by this epigenetic alteration in several kinds of tumours [24].

In recent studies, $P 14 A R F$ and $P 16 I N K 4 a$ promoter hypermethylation has been reported in many tumours, including gastric [25], breast [26], multiple myeloma [27], Leukemia [28], melanoma [29], and prostate cancer [30].

To determine whether promoter methylation has a useful role in managing urothelial cancer, the present study aimed to detect $P 14 A R F$ and P16INK $4 a$ promoter methylation by methylation-specific polymerase chain reaction (MS-PCR) from tumour and blood DNA of bladder cancer patients; and analyze the distribution of various clinicopathological parameters and some risk factors. To the best our knowledge, this is the first analysis of P14ARF and P16INK4a promoter methylation status in bladder cancer patients in Indian population.

\section{Materials and methods}

\subsection{Study subjects}

80 histologically confirmed incident bladder cancer speciments and matched blood samples were recruited from Department of Urology, Post Graduate Institute 
Table 1

Primer sequences for P16INK4a and P14ARF methylated and un-methylated

\begin{tabular}{|c|c|c|c|}
\hline Gene & Primer & Primer sequences & Reference \\
\hline \multirow[t]{6}{*}{ P14ARF } & M-Forward & 5'-GTCGAGTTCGGTTTTGGAGG-3 $^{\circ}$ & E.P. Xing et al. (1999) \\
\hline & M-Reverse & 5'-AAAACCACAACGACGAACG-3' & \\
\hline & UM-Forward & 5'-TGAGTTTGGTTTTGGAGGTGG-3‘ & \\
\hline & UM-Reverse & 5'-AACCACAACAACAAACACCCCT-3' & \\
\hline & M-Forward & 5‘-TTATTAGAGGGTGGGGCGGATCGC-3‘ & J. G. Herman et al. (1996) \\
\hline & M-Reverse & 5`-GACCCCGAACCGACCGTAA-3` & \\
\hline \multirow[t]{2}{*}{ P16INK4a } & UM-Forward & 5'-TTATTAGAGGGTGGGGTGGATTGT-3’ & \\
\hline & UM-Reverse & 5'-CAACCCCAAACCACAACCATAA-3‘ & \\
\hline
\end{tabular}

of Medical Education and Research, Chandigarh, India. None of the patients had received chemotherapy or radiation before inclusion.

The criteria for the selection of patient were based on clinical proforma, pathological, and histo-pathological records. This study was approved by the Ethical Committee of the Institute. Bladder tumour samples were reviewed by the study pathologist and classified according to the 1973 and 2004 WHO guidelines for bladder tumours (www.uroweb.org). Patients data were collected through interview where demographic features, clinical details, and environmental exposure were recorded using a standard clinical performa. For control group of patients who were admitted in hospital without any prior history of cancer, pre-cancerous lesions or acute inflammatory disease were selected. Cases and controls were matched by age, sex, and socio-economical status. Most of the subjects had completed their primary education.

A signed consent form was obtained from each of the patients. The amount of exposure to dangerous materials and chemicals in work place such as aromatic amines, polycyclic aromatic hydrocarbons and diesel were regarded as occupational exposure. Subjects who were exposed to such material over 5 years were classified as the high risk cases. Smoking habit was also studied among the subjects. Subjects who had smoked at least 100 cigarettes or chewed tobacco 100 times or more during their lifetimes were defined as smokers.

\section{Methods}

Tissues and matched blood samples from each case and blood samples were obtained from controls. DNA was extracted by a standard phenol/chloroform method. DNA samples were stored at $-20^{\circ} \mathrm{C}$ until analysis.

\section{Bisulphite treatment of DNA}

P16INK4a and P14ARF promoter methylation was analyzed in tumour and matched mononuclear blood cells. DNA methylation patterns in the $\mathrm{CpG}$ island of these genes were determined by methylation-specific PCR. Briefly, $1 \mu \mathrm{g}$ of DNA from tumour and blood cells was denatured by $\mathrm{NaOH}$, and subsequently treated with hydroquinone and sodium bisulfite at $55^{\circ} \mathrm{C}$ for $16 \mathrm{~h}$. Modified DNA samples were purified using the Wizard DNA purification following the Manufacturer instructions (Promega, USA) and eluted in $50 \mu \mathrm{l}$ of double distilled water. $\mathrm{NaOH}$ was added to complete the modification and followed by ethanol precipitation.

\section{Methylation specific PCR (MS-PCR)}

Resuspended DNA was used in a PCR reaction. Primer sequences and PCR conditions for P16INK4a and $P 14 A R F$ have been reported elsewhere [31,32], Table 1.

The reaction was carried out in a final volume of $50 \mu \mathrm{L}$ containing $50 \mathrm{ng}$ of bisulphite treated DNA. $1.5 \mathrm{mmol} / \mathrm{L}$ of $\mathrm{MgCl}_{2}, 0.2 \mathrm{mmol} / \mathrm{L}$ of each dNTP (Fermentas, USA), $200 \mu \mathrm{M}$ of each of the primers and 2.5 unit of Taq polymerase (Fermentas, USA). DNA was amplified during 30 cycles with an initial denaturation of 5 minutes at $95^{\circ} \mathrm{C}$ and a final extension of 5 minutes at $72^{\circ} \mathrm{C}$. The cycling program consisted of $30 \mathrm{sec}$ denaturation at $95^{\circ} \mathrm{C}, 30 \mathrm{sec}$ annealing at 61 and $65^{\circ} \mathrm{C}$ (P14ARF and P16INK4 $\alpha$ ) respectively, and $30 \mathrm{sec}$ extension at $72^{\circ} \mathrm{C}$. $\mathrm{PCR}$ products were electrophoresed on a $2 \%$ agarose gel. P14ARF methylated and unmethylated were recognized by 160 and 165 bp respectively, while for P16INK4a were identified by $150 \mathrm{bp}$ for methylated and $151 \mathrm{bp}$ for unmethylated (Figs 1, 2). In order to avoid misinterpretation of methylated and unmethylated product, reaction mixture for methylated and un-methylated primers were prepared separately.

\section{Statistical analysis}

Statistical analysis was carried out with SPSS 11.5 and EPI info 3.2 software programs. ORs were adjusted 


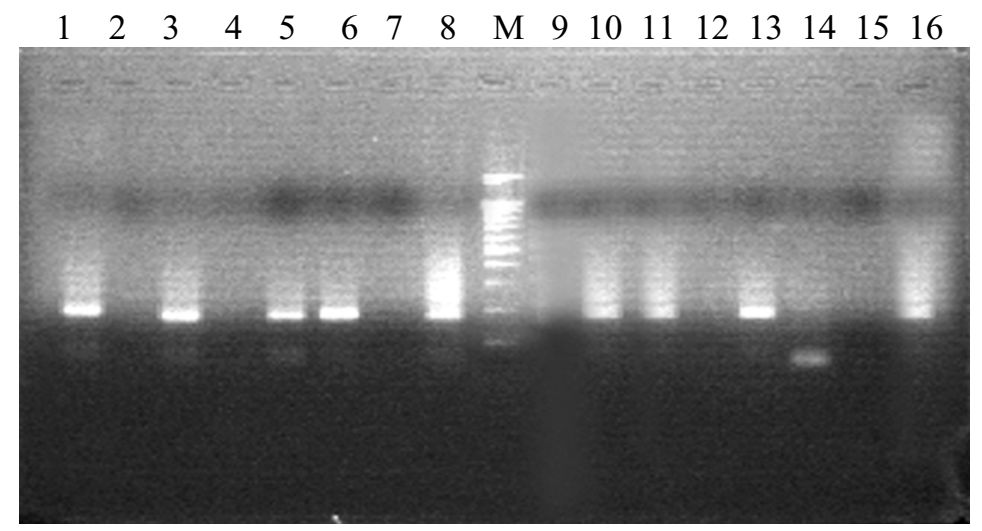

Lane M

Lane1

Lane2

Lane3,5,7,9,11,13,15:

Lane $4,6,8,10,12,14,16$ : 100-bp marker

Positive control

Negative control

Methylated (160 bp)

Unmethylated (165 bp)

Fig. 1. Methylation specific PCR for P14ARF of tissue samples.

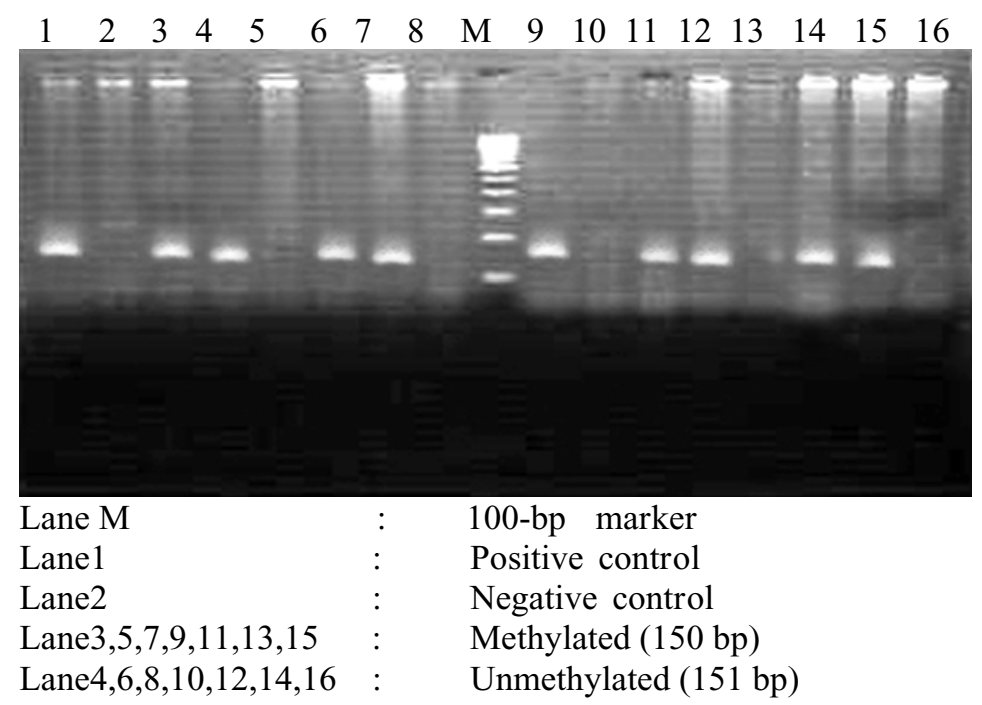

Fig. 2. Methylation specific PCR for P16INK4a of tissue samples.

for confounding factors, such as age, smoking, and socio-economical status. Multivariant analysis, odds ratios, and $95 \%$ confidence interval $(\mathrm{CI})$ were used to describe the strength of association.

\section{Results}

Demographic characteristics of cases and controls are summarized in Table 2 . The hypermethylation of $P 14 A R F$ and P16INK4 $\alpha$ genes were studies carried in
80 patients $(69(86.25 \%)$ males, and $11(13.75 \%)$ females) with mean age of 57.42 years. The control group consisted of $71(88.75 \%)$ males and $9(11.25 \%)$ healthy females with mean age of 56.35 years. $8.75 \%$ of patients and $32.50 \%$ of controls were current smokers and $36.25 \%$ of cases and $21.25 \%$ of controls had high risk jobs.

No hypermethylation of P14ARF and P16INK4 $\alpha$ were detected in peripheral blood sample of 80 cancerfree individuals.

P14ARF methylation was found in 18 out of 80 
Table 2

Demographic characteristic of cases with bladder cancer and healthy controls

\begin{tabular}{lcc}
\hline Variable & Cases & Controls \\
\hline Age (year) & & \\
Mean $( \pm$ SD) & $57.42( \pm 12.59)$ & $56.35( \pm 10.13)$ \\
Median range & $25-86$ & $30-85$ \\
Sex & & \\
-male & $69(86.25 \%)$ & $71(88.75 \%)$ \\
-female & $11(13.75 \%)$ & $9(11.25 \%)$ \\
Smoking & & \\
-current smokers & $31(38.75 \%)$ & $26(32.50 \%)$ \\
-non smokers & $49(61.25 \%)$ & $54(67.50 \%)$ \\
Job & & \\
-high risks & $29(36.25 \%)$ & $17(21.25 \%)$ \\
-low risks & $51(63.75 \%)$ & $63(78.75 \%)$ \\
Alcohol & & \\
-drinkers & $35(43.75 \%)$ & $29(36.25 \%)$ \\
-non drinkers & $45(56.25 \%)$ & $51(63.75 \%)$ \\
Stage & & \\
$\leqslant$ T1 (superficial) & $63(78.75 \%)$ & \\
$\geqslant$ T2 (invasive) & $17(21.25 \%)$ & \\
\hline
\end{tabular}

$(22.5 \%)$ tissue samples of bladder cancer patients. Among 18 cases with P14ARF methylation in tumour tissues, MS-PCR was able to detect the same change in the matching blood samples of $8(44.44 \%)$ cases. For the other 62 cases with no detected P14ARF methylation in tumour tissue, no signal was obtained on matching blood samples by using MS-PCR.

In tissue and matched blood samples of bladder cancer patients, the incidence of PI4ARF hypermethylation significantly increased $(\mathrm{OR}=0.31,95 \% \mathrm{CI}=$ $0.12-0.8, P=0.01)$ and $(\mathrm{OR}=0.0,95 \% \mathrm{CI}=0.0$ $0.62, P=0.006)$ respectively with an increase in age.

Clinicopathological analysis revealed that P14ARF hypermethylation in tissue and blood samples was significantly associated with invasive stage $(\geqslant \mathrm{T} 2)(\mathrm{OR}=$ $0.21,95 \% \mathrm{CI}=0.08-0.51, P=0.0002)$ and $(\mathrm{OR}=$ $0.09,95 \% \mathrm{CI}=0.03-0.37, P=0.00001)$ respectively (Table 3).

Of the bladder tumour samples amplified, 32 (40\%) presented PI6INK4 $\alpha$ promoter hypermethylation. Among 32 cases with P16INK4 $\alpha$ methylation in tumour tissues, MS-PCR was able to detect the same change in the matching blood samples of $12(37.5 \%)$ cases. For the other 48 cases with no detected P16INK $4 \alpha$ methylation in tumour tissue, no signal was obtained on matching blood samples by using MSPCR. Moreover, 41(51.25\%) tumour samples presented one of the P16INK4 $\alpha$ or P14ARF hypermethylation.

Table 4 shows the hypermethylation distribution of $P 16 I N K 4 \alpha$ gene along with various clinico-pathological parameters including age, smoking and stage of carcinoma in blood samples the patients. Muscle in- vasive tumour stage $(\geqslant \mathrm{T} 2)$ showed significant association with $P 16 I N K 4 \alpha$ promoter hypermethylation in tissue and blood samples of the patients $(\mathrm{OR}=0.38$, $95 \% \mathrm{CI}=0.17-0.82, P=0.01)$ and $(\mathrm{OR}=0.13$, $95 \% \mathrm{CI}=0.05-0.36, P=0.00005)$ respectively.

No association was found between P14ARF and $P 16 I N K 4 \alpha$ methylation with tobacco, high risk jobs and alcohol consuming in bladder cancer patients.

\section{Discussion}

There is growing evidence that DNA methylation of CDKN2A (INK4a/ARF) is an important mechanism of gene inactivation in cancer and its potential as a molecular marker has been regarded. This study has used methylation - specific PCR for the amplification of P14ARF and P16INK4a promoter regions in tumour tissue as well as matched blood DNA of cancer patients and healthy controls. We found promoter methylation in $47.1 \%$ of P14ARF and $58.8 \%$ of P16INK4a in the tissue samples of bladder cancer cases with invasive stage. These genes are involved in cell cycle regulation mechanisms [33]. Our finding have shown that methylation of these genes might be related with advanced stage and tumour metastasis. On the other hand, we found that hypermethylation at these genes loci detected in blood samples of patients are related to advanced disease stages. No promoter methylation was found in the blood DNA of control subjects. Detecting the same alteration in blood and tumour DNA indicated that the methylated DNA released into circulation may have derived from the primary tumour. This is confirmed other literature review which evident that methylation can occur in a tissue-specific or cancer-specific manner. Cancer-specific methylation is usually detected in tumour tissues and seldom observed in blood circulation unless in invasive stage [34,35].

We detected DNA methylation of blood samples of only metastatic cancer cases. Therefore blood DNA will not be useful for early detection of bladder cancer by these markers while urine sediment DNA might be more helpful in this regard. However, our results are indicating that blood DNA particularly might be useful for predicting patient survival and tumor progression from noninvasive to invasive stage. This was previously reported by other authors on the different type of cancers [36,37].

Moreover, our findings have provided strong evidence regarding the diagnostic potential of emerging epigenetic markers in bladder cancer patients. These 
Table 3

The relationship between $P 14 A R F$ promoter methylation and clinicopathological parameters of bladder cancer blood and tissue samples

\begin{tabular}{|c|c|c|c|c|c|c|c|c|}
\hline \multirow[t]{2}{*}{ Characteristic } & \multicolumn{2}{|c|}{ Overall } & \multicolumn{2}{|c|}{ Methylated } & \multicolumn{2}{|c|}{ UnMethylated } & \multicolumn{2}{|c|}{$P$ Value } \\
\hline & blood & tissue & blood & tissue & blood & tissue & blood & tissue \\
\hline \multicolumn{9}{|l|}{ Age $(n=80)$} \\
\hline$\leqslant 50$ & 22 & & $0(0.0 \%)$ & $2(9 \%)$ & $22(100 \%)$ & $20(91 \%)$ & 0.006 & 0.01 \\
\hline$>50$ & 58 & & $8(13.8 \%)$ & $16(27.58 \%)$ & $50(86.2 \%)$ & $42(72.42 \%)$ & & \\
\hline \multicolumn{9}{|l|}{ Smoking $(n=80)$} \\
\hline Smoker & 31 & & $5(16.1 \%)$ & $10(32.2 \%)$ & $26(83.9 \%)$ & $21(67.8 \%)$ & 0.2 & 0.1 \\
\hline Non smoker & 49 & & $3(6.1 \%)$ & $8(16.3 \%)$ & $46(93.9 \%)$ & $41(83.4 \%)$ & & \\
\hline \multicolumn{9}{|l|}{ Stages $(n=80)$} \\
\hline superficial $\leqslant \mathrm{T} 1$ & 63 & & $2(3.2 \%)$ & $10(15.9 \%)$ & $61(96.8 \%)$ & $53(84.1 \%)$ & 0.00001 & 0.0002 \\
\hline invasive $\geqslant \mathrm{T} 2$ & 17 & & $6(35.3 \%)$ & $8(47.1 \%)$ & $11(64.7 \%)$ & $9(52.9 \%)$ & & \\
\hline
\end{tabular}

Table 4

The relationship between P16INK4a promoter methylation and clinicopathological parameters of bladder cancer blood and tissue Samples

\begin{tabular}{|c|c|c|c|c|c|c|c|c|}
\hline \multirow[t]{2}{*}{ Characteristic } & \multicolumn{2}{|c|}{ Overall } & \multicolumn{2}{|c|}{ Methylated } & \multicolumn{2}{|c|}{ UnMethylated } & \multicolumn{2}{|c|}{$P$ Value } \\
\hline & blood & tissue & blood & tissue & blood & tissue & blood & tissue \\
\hline \multicolumn{9}{|l|}{ Age $(n=80)$} \\
\hline$\leqslant 50$ & 22 & & $3(13.6 \%)$ & $9(41 \%)$ & $19(86.4 \%)$ & $13(59 \%)$ & 0.95 & 0.95 \\
\hline$>50$ & 58 & & $9(15.5 \%)$ & $23(40 \%)$ & $49(85.5 \%)$ & $35(60 \%)$ & & \\
\hline \multicolumn{9}{|l|}{ Smoking $(n=80)$} \\
\hline Smoker & 31 & & $6(19.4 \%)$ & $14(45.2 \%)$ & $25(80.68 \%)$ & $17(54.8 \%)$ & 0.57 & 0.53 \\
\hline superficial $\leqslant \mathrm{T} 1$ & 63 & & $4(6.3 \%)$ & $22(34.9 \%)$ & $59(93.7 \%)$ & $41(65.1 \%)$ & 0.00005 & 0.01 \\
\hline invasive $\geqslant \mathrm{T} 2$ & 17 & & $8(47.1 \%)$ & $10(58.8 \%)$ & $9(52.9 \%)$ & $7(41.2 \%)$ & & \\
\hline
\end{tabular}

molecular assays may help developing more appropriate therapeutic interventions and management of clinical outcome. Inclusion of the other relevant tumor suppressor genes in the current panel of markers may increase the sensitivity of the assayOn the other hand, it is possible that some bladder tumour may not carry any epigenetic alteration and, thus, should be detected by other approaches, such as mutation analysis, $\mathrm{LOH}$ analysis, or detection of homozygous deletions [3840].

Aging is one of the main risk factors for cancer and the highest cancer rates exist among people over the age of 70 [41]. Epigenetic alterations closely related to the aging process have also been studied already and are proposed to be part of the primary processes contributing to age-related diseases such as cancer [42].

An increase in de novo methylation is an age-related event that occurs in normal tissue and may progress to regional hypermethylation, leading to silencing of specific genes important in the suppression of tumor formation [43]. There are some environmental and mitochondrial factors (intrinsic pathway of apoptosis) which can affect age-related methylation and cancer.

Environmental factors known to contribute to methylation alterations include carcinogen exposures, inflammation, and diet. Several carcinogen exposures such as tobacco, alcohol, arsenic, and asbestos have been associated with methylation-induced gene-inactivation in various human cancers including bladder cancer, head and neck squamous cell carcinoma, and mesothelioma [45-49].

It is therefore reasonable to suggest that various and potentially accumulating exposures throughout life may directly or indirectly lead to methylation alterations and impact disease susceptibility. In the present study, no significant association was found between the risk of tobacco, high risk job, alcohol consumption and P14ARF and P16INK4A hypermethylation. Controversially, Methylation of $\mathrm{CpG}$ islands in tobacco- associated cancers occurs in CDKN2A and directly or indirectly is induced by exposure to tobacco smoke in nonsmall-cell lung carcinoma [50]. Moreover, Wolff et al. (2008) observed that the prevalence of methylation at RUNX3 increased as a function of age at diagnosis and a history of smoking in bladder tumour.

Moreover, we found that the incidence of P14ARF hypermethylation significantly increased in the tissue and blood samples of bladder cancer patients with an increase in age. A study by Brock et al., (2009) has supported our findings and, in addition, they showed that age-related alterations in $\mathrm{CpG}$ loci were tissuedependent. More importantly, they suggested that the 
relationship between aging and promoter $\mathrm{CpG}$ methylation is complex.

On the other hand, other internal factors which are related to mitochondria and aging such as oxidative damage may have an effect on methylation and age-related cancer. It has been demonstrated that reactive oxygen species may cause oxidative damage and lead to mutations of mtDNA and alterations of the expression of several clusters of genes in aging tissues and senescent cells [53]. Mitochondrial defects have long been suspected to play an important role in the development and progression of cancer [54]. Xie et al., (2007) provided the first evidence regarding involvement of the mtDNA content in regulation of the promoter methylation and an effect on cancer.

Our results support previous and its current that methylation of some genes are tightly correlated in tumors as well as genes which show age-related methylation in bladder cancer [52]. Our data suggest that although environment factors have no effect on methylation, some mitochondrial factors (Intrinsic pathway factors) may play a role and need to be evaluated more.

Organ-specific panels of loci could be developed reflecting global epigenetic events. This would be small enough as a practical tool for routine applications. Further multi-institutional studies are required to validate these markers and their general applicability in the management of patients with urothelial cancer.

\section{Conclusion}

These results suggest that the $\mathrm{CpG}$ island hypermethylation status of the defined panel of genes may be a useful biomarker in patients suffering from bladder cancer.

\section{References}

[1] U.S. National Cancer Institute, bladder cancer. Available at: http://www.cancer.gov/bladder accessed November1, 2008.

[2] M. Vaish, A. Mandhani, R.D. Mittal and B. Mittal, Microsatellite instability as prognostic marker in bladder tumors: a clinical significance, BMC Urology 5 (2005), 2471-2490.

[3] D. Matthew, Galsky and W. Robert, Bladder Cancer, Text book of Kidney and Urinary Tract, 8th Edition. Wolters Kluwer: Lippincott Williams\&Wilkins Co., 2007, 777-785.

[4] M.P. Zeegers, R.A. Goldbohm and P.A. van den Brant, A prospective study on active and environmental tobacco smoking and bladder cancer risk, Cancer Causes Control 13(1) (2002), 83-86.

[5] http://www.oncologyradiation.com/, radiation-therapy-bladder-cancer.
[6] D. Sidransky, P. Frost, A. von Eschenbach, R. Oyasu, A.C. Preisinger and B. Vogelstein, Clonal origin of bladder cancer, N Engl J Med 326 (1992), 737-740.

[7] L. Mao, D.J. Lee, M.S. Tockman, Y.S. Erozan, F. Askin and D. Sidransky, Microsatellite alterations as clonal markers for the detection of human cancers, Proc Natl Acad Sci USA 91 (1994), 9871-9875.

[8] T. Habuchi, R. Takahashi, H. Yamada, Y. Kakehi, T. Sugiyama and O. Yoshida, Metachronous multifocal development of urothelial cancers by intraluminal seeding, Lancet 342 (1993), 1087-1088.

[9] I.H. Wong, Y.M. Lo and P.J. Johnson, Epigenetic tumor markers in plasma and serum: biology and applications to molecular diagnosis and disease monitoring, Ann N Y Acad Sci 945 (2001), 36-50.

[10] S.B. Baylin and J.G. Herman, DNA hypermethylation in tumorigenesis: epigenetics joins genetics, Trends Genet, 16 (2000), 168-174.

[11] P.A. Jones and S.B. Baylin, The fundamental role of epigenetic events in cancer, Nat Rev Genet 3 (2002), 415-428.

[12] M. Partha, Das and Rakesh Singal, DNA Methylation and Cancer, J Clin Oncol 22 (2004), 4632-4642. by American Society of Clinical Oncology.

[13] P.A. Jones and P.W. Laird, Cancer epigenetics comes of age, Nat Genet 21 (1999), 163-167.

[14] M. Esteller, CpG island hypermethylation and tumor suppressor genes: a booming present, a brighter future, Oncogene 21 (2002), 5427-5440.

[15] M. Esteller, Relevance of DNA methylation in the management of cancer, Lancet Oncol 4 (2003), 351-358.

[16] A. Patel, J.D. Groopman and A. Umar, DNA methylation as a cancerspecific biomarker: from molecules to populations, Ann N Y Acad Sci 983 (2003), 286-297.

[17] S.E. Cottrell and P.W. Laird, Sensitive detection of DNA methylation, Ann N Y Acad Sci 983 (2003), 120-130.

[18] P.W. Laird, The power and the promise of DNA methylation markers, Nat Rev Cancer 3 (2003), 253-266.

[19] J. Hayslip and A. Montero, Tumor suppressor gene methylation in follicular lymphoma: a comprehensive review, Molecular Cancer 5 (2006), 44-48.

[20] J.C. Richard, P.W. Laird and R.H. Datar, Promoter Hypermethylation. A New Therapeutic Target Emerges in Urothelial Cancer, Journal of Clinical Oncology 23(13) (2005), 28792881.

[21] M.W. Chan, L.W. Chan and N.L. Tang, Frequent hypermethylation of promoter region of RASSF1A in tumor tissues and voided urine of urinary bladder cancer patients, Int J Cancer 104 (2003), 611-616.

[22] L.L. Chang, W.T. Yeh and S.Y. Yang, Genetic alterations of p16INK4a and p14ARF genes in human bladder cancer, $J$ Urol 170 (2003), 595-600.

[23] Y. Horikawa, K. Sugano and M. Shigyo, Hypermethylation of an E-cadherin $(\mathrm{CDH} 1)$ promoter region in high grade transitional cell carcinoma of the bladder comprising carcinoma in situ, J Urol 169 (2003), 1541-1545.

[24] G. Dominguez, J. Silva and J.M. Garcia, Prevalence of aberrant methylation of p14ARF over p16INK4a in some human primary tumors, Mutat Res 530 (2003), 9-17.

[25] C. Bernal, F. Aguayo, C. Villarroel, M. Vargas, I. Díaz, F.J. Ossandon, E. Santibáñez, M. Palma, E. Aravena, C. Barrientos and A.H. Corvalan, Reprimo as a potential biomarker for early detection in gastric cancer, Clin Cancer Res 14(19) (2008), 6264-6269.

[26] G. Sharma, S. Mirza, C.P. Prasad, A. Srivastava, S.D. Gupta 
and R. Ralhan, Promoter hypermethylation of $p 16^{I N K 4 A}$, $p 14^{A R F}$, CyclinD2 and Slit2 in serum and tumor DNA from breast cancer patients, Life Science $\mathbf{8 0}$ (2007), 1873-1881.

[27] C.S. Chim, Y.L. Kwong and R. Liang, Gene hypermethylation in multiple myeloma: lessons from a cancer pathway approach, Clin Lymphoma Myeloma 8(6) (2008), 331-339.

[28] R.T. Williams and C.J. Sherr, The INK4-ARF (CDKN2A/B) Locus in Hematopoiesis and BCR-ABL-induced Leukemias, Cold Spring Harb Symp Quant Biol. 2008 Nov 26. [Epub ahead of print].

[29] S.J. Gallagher, J.F. Thompson, J. Indsto, L.L. Scurr, M. Lett, B.F. Gao, R. Dunleavey, G.J. Mann, R.F. Kefford and H. Rizos, p16INK4a expression and absence of activated B-RAF are independent predictors of chemosensitivity in melanoma tumors, Neoplasia 10(11) (2008), 1231-1239.

[30] C. Fan, L. He, A. Kapoor, A. Gillis, A.P. Rybak, J.C. Cutz and D. Tang, Bmil promotes prostate tumorigenesis via inhibiting p16(INK4A) and p14(ARF) expression, Biochim Biophys Acta 1782(11) (2008), 642-648.

[31] J.G. Herman, J.R. Graff, S. Myöhänen, B.D. Nelkin and S.B. Baylin, Methylation-specific PCR: a novel PCR assay for methylation status of CpG islands, PNAS 93 (1996), 98219826.

[32] E.P. Xing, Y. Nie, Y. Song, G.Y. Yang, Y.C. Cai, L.D. Wang and C.S. Yang, Mechanisms of inactivation of p14ARF, p15INK4b, and p16INK4a genes in human esophageal squamous cell carcinoma, Clin Cancer Res 5(10) (1999), 27042713.

[33] J.F. Viallard, F. Lacombe, F. Belloc, J.L. Pellegrin and J. Reiffers, Molecular mechanisms controlling the cell cycle: fundamental aspects and implications for oncology, Cancer Radiother 5(2) (2001), 109-129.

[34] K. Yamashita, S. Upadhyay and M. Osada, Pharmacologic unmasking of epigenetically silenced tumor suppressor genes in esophageal squamous cell carcinoma, Cancer Cell 2 (2002), 485-495.

[35] C. Jeronimo, R. Henrique and M.O. Hoque, A quantitative promoter methylation profile of prostate cancer, Clin Cancer Res 10 (2004), 8472-8478.

[36] D.R. Yates, I. Rehman, M.F. Abbod, M. Meuth, S.S. Cross, D.A. Linkens, F.C. Hamdy and J.W.F. Catto, Promoter Hypermethylation Identifies Progression Risk in Bladder, CancerClinical Cancer Research 13 (2007), 2046.

[37] L. Shen, H. Kantarjian, Y. Guo, E. Lin, J. Shan, X. Huang, D. Berry, S. Ahmed, W. Zhu, Sh. Pierce, Y. Kondo, Y. Oki, J.Jelinek, H. Saba, E. Estey and J.J. Issa, DNA Methylation Predicts Survival and Response to Therapy in Patients With Myelodysplastic Syndromes, Journal of Clinical Oncology 28(4) (2010), 605-613.

[38] L. Mao, M.P. Schoenberg, M. Scicchitano, Y.S. Erozan, A. Merlo and D. Schwab, Molecular detection of primary bladder cancer by microsatellite analysis, Science 271 (1996), 659662.

[39] G. Steiner, M.P. Schoenberg, J.F. Linn, L. Mao and D. Sidransky, Detection of bladder cancer recurrence by microsatellite analysis of urine, Nat Med 3 (1997), 621-624.

[40] P. Cairns, T.J. Polascik, Y. Eby, K. Tokino, J. Califano and A. Merlo, Frequency of homozygous deletion at p16/CDKN2 in primary human tumours, Nat Genet 11 (1995),210-212.

[41] M. Esteller, M.F. Fraga, M.F. Paz, E. Campo, D. Colomer, F.J. Novo, M.J. Calasanz, O. Galm, M. Guo, J. Benitez and
J.G. Herman, Cancer epigenetics and methylation, Science 297 (2002), 1807-1808.

[42] M.D. Shahbazian and H.Y. Zoghbi, Rett syndrome and $\mathrm{MeCP} 2$ : linking epigenetics and neuronal function, Am J Hum Genet 71 (2002), 1259-1272.

[43] N. Lopatina, J.F. Haskell, L.G. Andrews, J.C. Poole, S.Saldanha and T.O. Tollefsbol, Differential maintenance and de novo methylating activity by three DNA methyltransferases in aging and immortalized fibroblasts, J Cell Biochem $\mathbf{8 4}$ (2002), 324-334.

[44] B.C. Christensen, J.J. Godleski, C.J. Marsit, E.A. Houseman and C.Y. Lopez-Fagundo. Asbestos exposure predicts cell cycle control gene promoter methylation in pleural mesothelioma, Carcinogenesis 29 (2008), 1555-1559.

[45] C.J. Marsit, E.A. Houseman, A.R. Schned, M.R. Karagas and K.T. Kelsey, Promoter hypermethylation is associated with current smoking, age, gender and survival in bladder cancer, Carcinogenesis 28 (2007), 1745-1751.

[46] C.J. Marsit, M.D. McClean, C.S. Furniss and K.T. Kelsey, Epigenetic inactivation of the SFRP genes is associated with drinking, smoking and HPV in head and neck squamous cell carcinoma, Int J Cancer 119 (2006), 1761-1766.

[47] S. Toyooka, R. Maruyama, K.O. Toyooka, D. McLerran and Z. Feng, Smoke exposure, histologic type and geography-related differences in the methylation profiles of non-small cell lung cancer, Int J Cancer 103 (2003), 153-160.

[48] C.M. Lyon, D.M. Klinge, K.C. Liechty, F.D. Gentry and T.H. March, Radiation-induced lung adenocarcinoma is associated with increased frequency of genes inactivated by promoter hypermethylation, Radiat Res 168 (2007), 409-414.

[49] B.C. Christensen, E.A. Houseman, J.J. Godleski, C.J. Marsit, J.L. Longacker, Epigenetic profiles distinguish pleural mesothelioma from normal pleura and predict lung asbestos burden and clinical outcome, Cancer Res, 2008.

[50] D.H. Kim, H.H. Nelson, J.K. Wiencke, D.C. Christiani, J.C. Wain, E.J. Mark and K.T. Kelsey, Promoter hypermethylation of DAP-kinase: association with advanced stage in non-small cell lung cancer, Oncogene, 2001, in press.

[51] E.M. Wolff, G. Liang, C.C. Cortez, Y.C. Tsai, J.E. Castelao, V.K. Cortessis, D.D. Tsao-Wei, S. Groshen and P.A. Jones, RUNX3 Methylation Reveals that Bladder Tumors Are Older in Patients with a History of Smoking, Cancer Research 68 (2008), 6208-6214.

[52] C. Ch. Brock, E.A. Houseman, J.M. Carmen, Sh. Zheng, R.W. Margaret, J.L. Wiemels, H.H. Nelson, M.R. Karagas, J.F. Padbury, R. Bueno, D.J. Sugarbaker, R. Yeh, J.K. Wiencke and K.T. Kelsey, Aging and Environmental Exposures Alter Tissue-Specific DNA Methylation Dependent upon CpG Island Context, PLoS Genet 5(8) (2009), e1000602.

[53] Y. Wei, S. Wu, Y. Ma and H. Lee, Respiratory Function Decline and DNA Mutation in Mitochondria, Oxidative Stress and Altered Gene Expression during Aging, Chang Gung Med J 32 (2009), 113-132.

[54] W.C. Copeland, J.T. Wachsman, F.M. Johnson and J.S. Penta, Mitochondrial DNA alterations in cancer, Cancer Invest 20 (2002), 557-569.

[55] C. Xie, A. Naito, T. Mizumachi, T.T. Evans, M.G. Douglas, C.A. Cooney, C. Fan and M. Higuchi, Mitochondrial regulation of Cancer Associated Nuclear DNA Methylation, Biochem Biophys Res Commun 364(3) (2007), 656-661. 


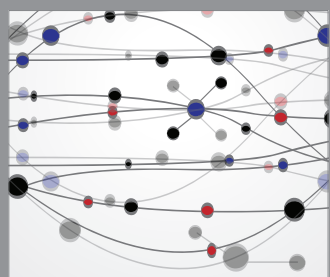

The Scientific World Journal
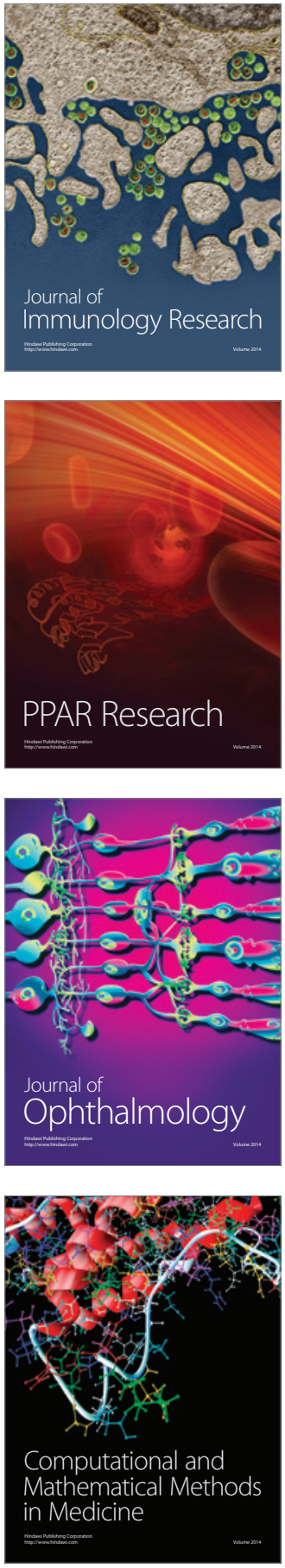

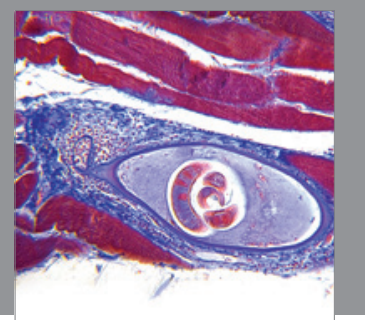

Gastroenterology

Research and Practice
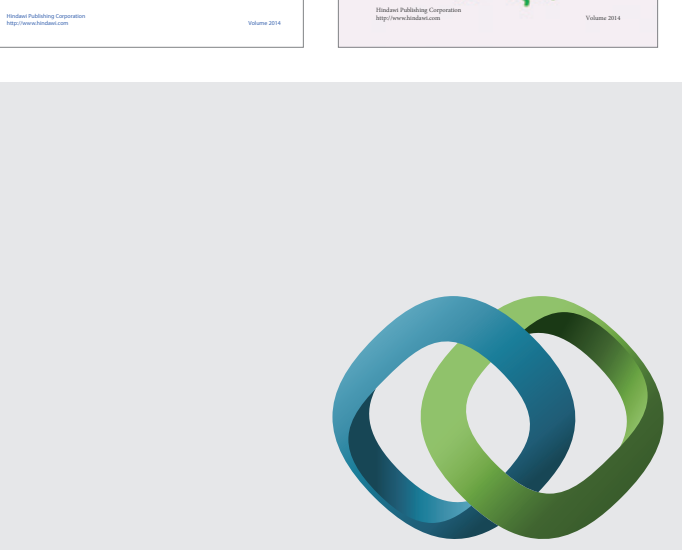

\section{Hindawi}

Submit your manuscripts at

http://www.hindawi.com
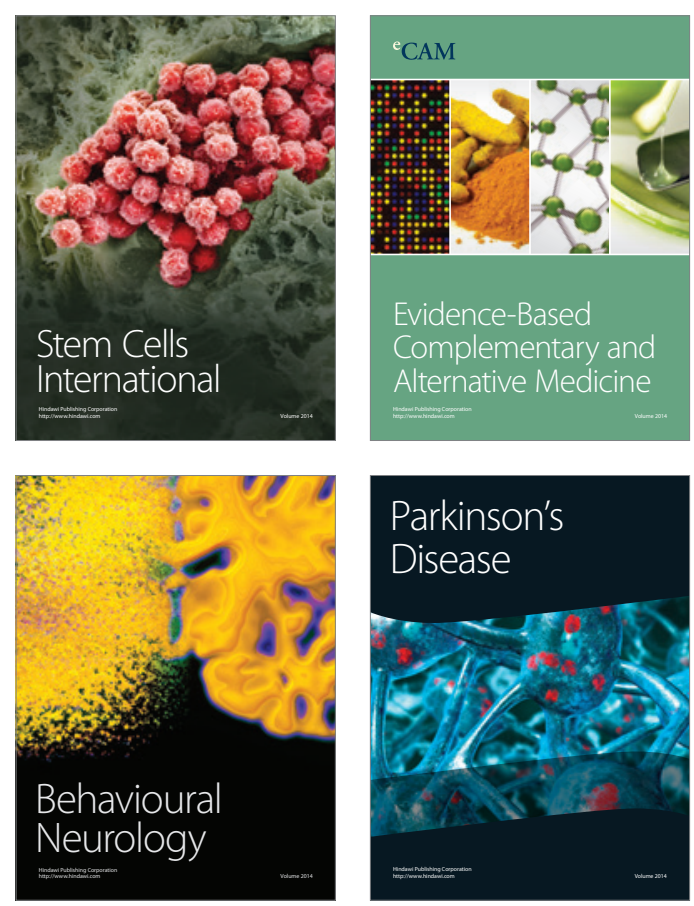

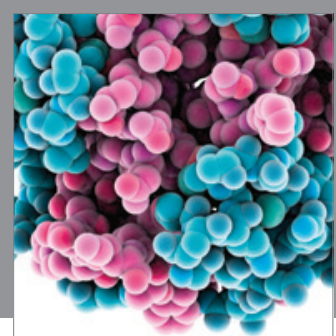

Journal of
Diabetes Research

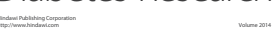

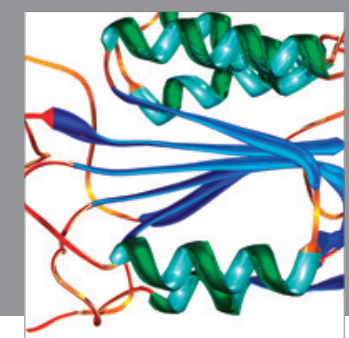

Disease Markers
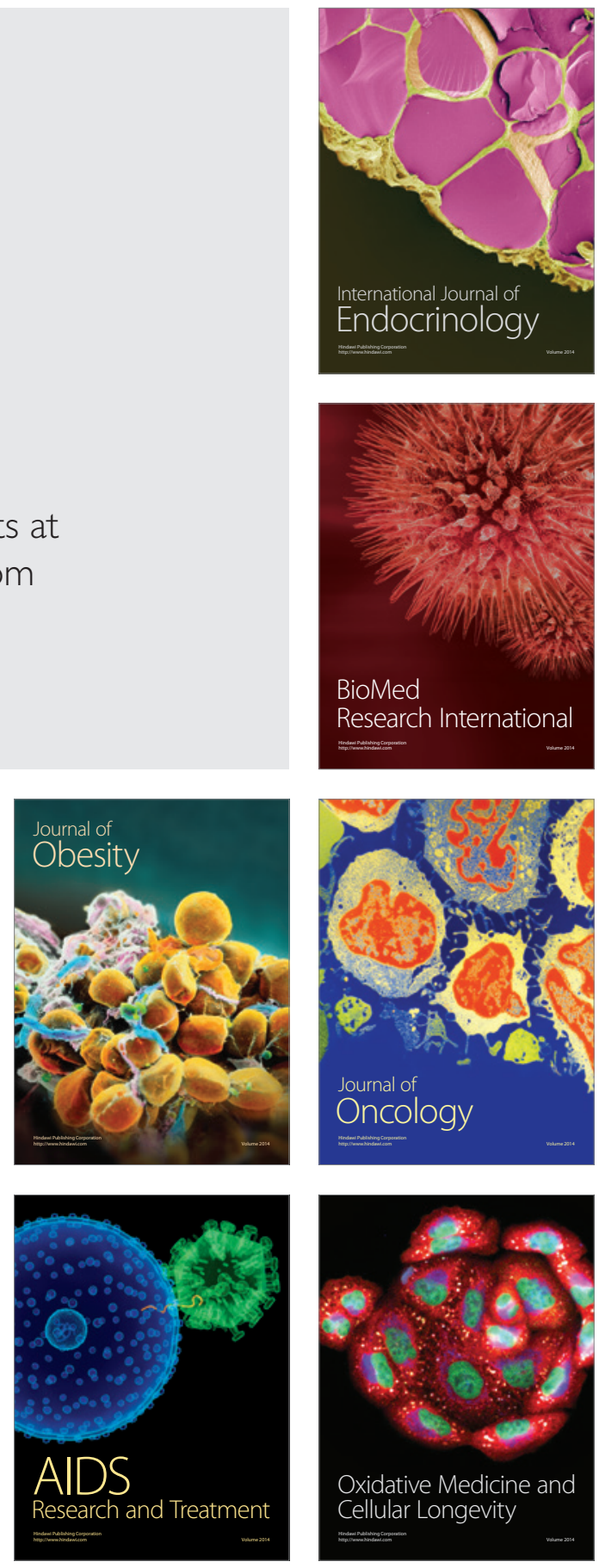